\title{
A Study of Perceived Stress, Suicidal Ideation and Religiosity among Young Adults
}

\author{
Sana Shafi ${ }^{1}$, Dr. Touseef Rizvi ${ }^{2}$
}

\section{ABSTRACT}

Stress is the extent to which individuals perceive that their demands exceed their ability to cope. Stressful events in an external or internal environment of a person can result in illness or suffering if there is failure to adapt oneself to change. The amount of stress that young adults face nowadays is very high. Due to strain of studies, the constant worrying about job availability and general lifestyle changes, a large increase in suicidal attempts has been seen. But even in these dire circumstances, there seems to be a buffering role of religiosity against stress in the young adults. The present research venture was aimed to study the relation between perceived stress, suicidal ideation and religiosity among young adults. The sample consisted of 60 young adults (students) taken from various colleges from different parts of the Kashmir valley. The results of the study revealed that there was positive correlation between perceived stress and suicidal ideation, negative correlation between perceived stress and religiosity and no correlation between religiosity and suicidal ideation among young adults.

Keywords: Stress, Suicidal Ideation, Religiosity, Young Adults.

Stress is an internal state that is caused by the physical demands on the body or by environmental and social situations. Many ongoing situations like noise, traffic, weather conditions and even everyday issues involving family, work, health etc are stressors. Stress is a negative emotional experience accompanied by predictable biochemical, physiological, cognitive and behavioural changes that are directed either towards altering the event or accommodating to its effects.

Suicidal ideation is a term for thoughts about or an unusual preoccupation with suicide. The range of these thoughts range from fleeting to detailed planning, role playing and unsuccessful attempts. It is a distressing phenomenon because other people are unable to directly occupy the mental world of the suicidal. Stressful life events are strong predictors of increased risk for suicidal ideation. Life events like alcohol abuse, unemployment, bullying, loss of family and/or friends community violence etc have shown to increase the risk of suicidal ideation. Suicide is

\footnotetext{
${ }^{1}$ Phd Scholar Dept of Psychology, University of Kashmir

${ }^{2}$ Asst Prof, Dept Of Psychology, University Of Kashmir

(c) 2015 I S Shafi, T Rizvi; licensee IJIP. This is an Open Access Research distributed under the terms of the Creative Commons Attribution License (http://creativecommons.org/licenses/by/2.0), which permits unrestricted use, distribution, and reproduction in any Medium, provided the original work is properly cited.
} 


\section{A Study of Perceived Stress, Suicidal Ideation and Religiosity among Young Adults}

associated with many sources of distress including hopelessness, intolerable stress and helplessness (Kaplan, Sadock, Grebb, 1994).

Religiosity is a comprehensive sociological term used to refer to the numerous aspects of religious activity, dedication and belief. In its narrowest sense, religiosity deals more with how religious a person than how a person is religious.

Studies have shown that stress and lack of meaning in life foster suicidal ideation, but major sources of suicidal ideation were related to religion. (Israelashvili \& Mualem, 1991). Stack and Lester (1991) worked on the impact of religion on suicide, but they didn't find consistent results. However, they found that greater the church attendance, lower was the approval of suicide. They also found that the effect of religiosity on suicidal ideation is independent of education, gender, marital status and age. Greater levels of religiosity are found to be associated with a decreased risk of suicidal behaviour (Lizardi \& Gearing, 2010).

The results of a study by Kristine Brown (2011) provided confirmation that depression, hopelessness, perceived stress, and suicide attitudes are independent predictors of suicide thoughts. The researcher confirmed that increased levels of depression, hopelessness and perceived stress are considerably related to and predictive of suicide ideation among college students. These findings are congruent with past research and provide further evidence that depression, hopelessness, perceived stress, and suicide attitudes are risk factors for suicide ideation.

Countries with higher religiosity tend to have lower suicide rates (Pelham \& Nyiri, 2005). Religious worship attendance was associated with decreased risk of past twelve month suicide attempts in the general population (Rasic, Belik, Elias, Katz, Enns \& Sareen, 2008). Religiosity affects the way people think about the stressful situation, but it does not affect the proportion of positive consequences perceived as outcomes of the events nor the causal attribution examined (Leowenthal, Macleod, Goldblatt, Lubitsh \& Valentine, 2000).

An individual's commitment to core religious beliefs is protective against suicide (Stack, 1983; Stack \& Kposowa, 2011). It has been seen that life events play an important role in the process of suicide as risk and precipitating factors and that suicidal individuals have lower levels of social support and disrupted social networks (Heikkinen, Aro, \& Lonnqvist, 1993). In a study conducted by Dervic, et.al, it was seen that religiously unaffiliated subjects had significantly more lifetime suicide attempts and more first-degree relatives who committed suicide than subjects who endorsed a religious affiliation, which suggests that adherents to any of the major religious traditions are more likely to be religiously integrated and religious affiliation is correlated with fewer suicide attempts (Dervic, K., Oquendo, M. A., Grunebaum, M. F., Ellis, S., Burke, A. K. \& Mann, J. J. 2004).

In a study conducted by Eun-Ok Park and Hyo Young Lee (2015), it was found that perceived bad health, stress, and depression had a significant influence on suicidal ideation in all age 
groups. Religiosity, influence of religion and church attendance were significantly negatively associated with suicidal ideation in a research done by Joseph D. Hovey (1999).

\section{OBJECTIVES}

- To find the correlation between perceived stress and suicidal ideation among young adults.

- $\quad$ To find the correlation between perceived stress and religiosity among young adults.

- $\quad$ To find the correlation between suicidal ideation and religiosity among young adults.

\section{METHODOLOGY}

\section{Sample:}

The sample consisted of 60 young adults taken from different parts of Kashmir.

\section{Tools Used:}

Perceived Stress Scale (PSS, 1983) (S.Cohen, T. Kamarck, R. Mermelstein). This is a 14 item questionnaire developed to assess the stress domains of unpredictability, lack of control, burden overload and stressful life circumstances. From all items, the respondents specify the frequency of the feeling, thoughts or circumstances described on a 5-point Likert scale ranging from 0 (never) to 4(very often).

Beck Scale for Suicidal Ideation BSS (BSS, 1991) (Aaron T. Beck, Robert A. Steer). The BSS is a 21-item self report questionnaire that may be used to identify and assesses the presence and severity of suicidal ideation. It also assesses the respondent's suicidal plans, deterrents to suicide and the level of openness to revealing suicidal thoughts. The reliability coefficient has been reported to be 0.87 and test-retest reliability 0.54 .

Deka and Broota's Religiosity Scale (Deka J., Broota K.D. 1988). The religiosity scale consists of 44 items which measure the level of religious faith and belief in God. The items are not specific to any religion and therefore can be used on all religious groups. The items also attempt to tap the extent of a subject's adherence to the doctrines of his/her religious faith. The items are rated on a 5-point scale. The reliability coefficient has been reported to be 0.96

\section{Statistical Techniques Used:}

The data collected was analysed used various statistical techniques, keeping in view the objectives of the study. T-test, quartile, percentage and Pearson's correlation coefficient were used.

\section{Procedure:}

The subjects were personally approached in different colleges and instructed to give their responses on a questionnaire booklet. The respondents were given assurance of confidentiality to boost their motivation and reduce bias. After motivating the respondents, the questionnaires were distributed and necessary assistance was provided by the researcher where ever required. 


\section{RESULTS AND INTERPRETATION:}

Table 1: Showing frequency and percentage of sample group on perceived stress:

\begin{tabular}{|l|l|l|}
\hline Perceived Stress & Frequency & \%age \\
\hline Low & 15 & 25 \\
\hline Average & 32 & 53.34 \\
\hline High & 13 & 21.66 \\
\hline
\end{tabular}

The above table shows the frequency and percentage of perceived stress among young adults. From the table it is evident that 15 out of 60 (25\%) of subjects that fall in level Q1 (20.48) and below are low in perceived stress, 32 out of 60 (53.34\%) subjects that fall between levels Q1-Q3 are average in perceived stress and 13 out of 60 (21.66\%) subjects that fall in level Q3 (29.72) and above are high in perceived stress.

Table 2: Showing frequency and percentage of sample group on suicidal ideation:

\begin{tabular}{|l|l|l|}
\hline & Frequency & \%age \\
\hline Presence of Suicidal Ideation & 8 & 13.3 \\
\hline Absence of Suicidal Ideation & 52 & 86.7 \\
\hline
\end{tabular}

From the above table it is evident that 8 out of 60 (13.33\%) of subjects show suicidal ideation and 52 out of $60(86.7 \%)$ show no suicidal ideation.

Table 3: Showing frequency and percentage of sample group on religiosity:

\begin{tabular}{|l|l|l|}
\hline Religiosity & Frequency & \%age \\
\hline Low & 15 & 25 \\
\hline Average & 33 & 55 \\
\hline High & 12 & 20 \\
\hline
\end{tabular}

From the table it is evident that 15 out of 60 (25\%) subjects that fall in level Q1 (107.5) and below are low in religiosity, 33 out of 60 (55\%) subjects that fall in between levels Q1-Q3 are average in religiosity and 12 out of 60 (20\%) subjects that fall in level Q3 (146.7) and above are high in religiosity. 
Table4: Correlation between Perceived Stress and Suicidal Ideation

\begin{tabular}{|l|l|}
\hline Perceived Stress & $\mathrm{r}=0.42^{*}$ \\
\hline Suicidal Ideation & \\
\hline * Correlation significant at 0.05 level & \\
\hline
\end{tabular}

The above table shows the correlation of perceived stress with suicidal ideation, and it is evident from the table that there is a significant correlation between perceived stress and suicidal ideation.

Table5: Correlation between Perceived Stress and Religiosity

\begin{tabular}{|l|l|}
\hline Perceived Stress & \\
\cline { 1 - 2 } Religiosity & $\mathrm{r}=0.34^{*}$ \\
& \\
\hline
\end{tabular}

* Correlation significant at 0.05 level $\quad \mathrm{N}=60$

The above table shows the correlation of perceived stress with religiosity, and it is evident from the table that there is a significant correlation between perceived stress and religiosity.

Table6: Correlation between Suicidal Ideation and Religiosity

\begin{tabular}{|l|l|}
\hline Suicidal Ideation & \\
\hline Religiosity & $\mathrm{r}=0.13^{\mathrm{NS}}$ \\
& \\
\hline
\end{tabular}

$\mathrm{N}=60$

The above table shows the correlation of suicidal ideation with religiosity, and it is evident from the table that there is no significant correlation between suicidal ideation and religiosity.

\section{DISCUSSION}

The present study was aimed to assess Perceived Stress, Suicidal Ideation and Religiosity among young adults, correlation of Perceived Stress with Suicidal Ideation and Religiosity, and correlation of Suicidal Ideation with Religiosity among young adults.

The study revealed that of the 60 young adults, perceived stress was found to be high among $21.66 \%$ of the population, $53.34 \%$ of the population were having average perceived stress and $25 \%$ of the population was low on perceived stress. As far as suicidal ideation is concerned, only $13.34 \%$ of the population showed suicidal ideation and $86.7 \%$ showed no suicidal ideation. Religiosity was found to be high among $20 \%$ of the population, average in $55 \%$ and low in $25 \%$ of the population. 


\section{A Study of Perceived Stress, Suicidal Ideation and Religiosity among Young Adults}

There was positive correlation between perceived stress and suicidal ideation, negative correlation between perceived stress and religiosity and no correlation between religiosity and suicidal ideation among young adults.

\section{REFERENCES}

Dervic, K., Oquendo, M. A., Grunebaum, M. F., Ellis, S., Burke, A. K., \& Mann, J. J. (2004). Religious affiliation and suicide attempt. American Journal of Psychiatry, 161, 23032308.

Eun-Ok Park and Hyo Young Lee (2015). Factors Influencing Suicidal Ideation Among Korean Adults by Age: Results of the 2010-2011 Korean Health and Nutrition Examination Survey. Community Mental Health Journal.

Heikkinen, M., Aro, H., \& Lonnqvist, J. (1993). Life Events and Social Support In Suicide. Suicide Life Threat Behaviour, 23(4), 343-358.

HOVEY J. D. (1999) Religion and Suicidal Ideation in a Sample Of Latin American Immigrants. Psychological Reports: Volume 85, Issue, pp. 171-177.

Israelashvili, M., Mualem, H. K. (1991) Culture as a Vector: The Case of Suicidal Ideation Among Arab Adolescents Living in Israel. Retrieved from: www.preventionresearch.org/Final_Press [Accessed on 31st March, 2014].

Kaplan, H. I., Sadock, B. J. \& Grebb, J. A. (1994). Kaplan and Sadock’s Synopsis of Psychiatry: Behavioural Science's Clinical Psychiatry.

Lizardi, D. D., \& Gearing, R. R. (2010). Religion and Suicide: Buddhism, Native American and African Religions, Atheism and Agnosticism. Journal of Religion \& Health, 49 (3), 377384.

Loewenthal, K. M., MacLeod, A. K., Goldblatt, V., Lubitsh, G., \& Valentine, J. D. (2000). Comfort and Joy: Religion, Cognition and Mood in Individuals under Stress. Cognition \& Emotion, 14, 355-374.

Mowat, H., Swinton, J., Stark, C., \& Mowat, D. (2006). Religion and Suicide: Exploring the Role Of The Church In Deaths By Suicide In Highland, Scotland.

Pelham, B., Nyiri, Z. (2008). In More Religious Countries, Lower Suicide Rates. Retrieved from: www.gallup.com/poll/108625/More-Religious-Countries-Lower-Suicide-Rates.aspx.

[Accessed on 30th March, 2014].

Rasic, D. T., Belik, S. L., Elias, B., Katz, L. Y., Enns M., Sareen, J. (2008). Spirituality, Religion \& Suicidal Behaviour in a Nationally Representative Sample. Affective Disorders, 114 (1-3): 32-40.

Stack, S. (1983). The Effect Of Religious Commitment On Suicide: A Cross-National Analysis. Journal of Health And Social Behaviour, 24, 362-374.

Stack, S., \& Kposowa, A. J. (2011). Religion and Suicide Acceptability: a Cross-National Analysis. Journal for the Scientific Study of Religion, 50 (2), 289-306.

Stack, S., \& Lester, D. (1991). The Effect of Religion on Suicide Ideation. Social Psychiatry and Psychiatric Epidemiology, 26, 168-170. 